\title{
Cross Sectional Study of Skin Carriage and Enterotoxigenicity of Staphylococcus aureus among Food Handlers
}

\author{
Moustafa El-Shenawy¹, Mohamed Tawfeek ${ }^{1}$, Lobna El-Hosseiny², Mohamed El-Shenawy ${ }^{3}$, \\ Aida Farag3, Hoda Baghdadi², Ola Saleh1', Jordi Mañes' ${ }^{4}$, José Miguel Soriano ${ }^{4}$ \\ ${ }^{1}$ Department of Food Microbiology, National Research Center, Cairo, Egypt \\ ${ }^{2}$ Department of Environmental Studies, Institute of Graduate Studies and Research, Alexandria University, \\ Alexandria, Egypt \\ ${ }^{3}$ Department of Microbiology, National Institute of Oceanography and Fisheries, Alexandria, Egypt \\ ${ }^{4}$ Observatory of Nutrition and Food Safety in Developing Countries, Department of Preventive Medicine and \\ Public Health, Faculty of Pharmacy, University of Valencia, Burjassot, Spain \\ Email: $\underline{m}$ elshenawy@hotmail.com
}

Received 30 December 2013; revised 29 January 2014; accepted 7 February 2014

Copyright (C) 2014 by authors and Scientific Research Publishing Inc.

This work is licensed under the Creative Commons Attribution International License (CC BY). http://creativecommons.org/licenses/by/4.0/

\section{Abstract}

The prevalence of enterotoxigenic Staphylococcus aureus was investigated among 200 participants working in three different food processing plants in Egypt. Using skin swabs, 75 (38\%) of the 200 tested persons were positive for the presence of $S$. aureus. Of the $S$. aureus positive persons, 28 $(14 \%)$ harboured $S$. aureus produced staphylococcal enterotoxins. The serotypes of these enterotoxins were enterotoxin A (68\%), enterotoxin B (36\%), enterotoxin C $(46 \%)$ and enterotoxin $D$ $(18 \%)$. Some of these isolates produced more than one type of enterotoxins namely $A B, A C, B C, B D$, $\mathrm{ABC}$ and ACD. Analysis of risk factors implicated in skin carriage of $S$. aureus as age, gender, marital status, education, duration in employment, frequency and method of hand wash and incidence of chronic skin infection revealed insignificant association with staphylococcal skin carriage. The obtained results put forth the risk of food contracting contamination with enterotoxigenic strains of $S$. aureus owing to skin colonization of $S$. aureus among food handlers.

\section{Keywords}

Enterotoxigenic S. aureus; Skin Carriage; Risk Factors; Food Handlers

\section{Introduction}

Food borne diseases are a major public health concern. They cause personal distress, preventable death and

How to cite this paper: El-Shenawy, M., et al. (2014) Cross Sectional Study of Skin Carriage and Enterotoxigenicity of Staphylococcus aureus among Food Handlers. Open Journal of Medical Microbiology, 4, 16-22. 
avoidable economic burden. The true incidence of foodborne diseases is difficult to quantify. In industrialized countries, it is estimated that every year more than $30 \%$ are exposed to foodborne diseases [1]. Risk factors implicated in foodborne diseases as identified by Centers for Disease Control and Prevention included unsafe sources, inadequate cooking, improper holding, contaminated equipment and poor personal hygiene implicating that the food handler dimension is crucially important [2].

Food handlers have been implicated in a plethora of foodborne diseases. It has been reported that one of the important pathogens often transmitted via food contaminated by infected food handlers is Staphylococcus aureus. This versatile pathogen is very well adapted to colonize the human skin and the human body provides some major ecological niches for this species. The anterior nares is the most frequent carriage site for $S$. aureus, nonetheless extranasal sites typically harbor the organism including the skin, perineum and pharynx [3] [4].

Until recently, reports on food contamination by $S$. aureus were mainly limited to occasional detections in the environment, the source of food and food itself. However, it is reported that human carriers are the most important source for transmission and the association between food handlers and the transmission of food borne disease frequently presents an investigative challenge [5]. Consideration into risk factors, transmission routes and many aspects of prevalence of carriage of foodborne pathogens among food handlers to eliminate carriage is necessary. Bodies concerned with food safety are left to consider whether interventions such as decolonization, continued monitoring or restrictions in the occupational activities are required [6].

Although skin carriage of $S$. aureus is less reported than nasal carriage, little is known about the prevalence and risk of skin carriage of enterotoxigenic strains of $S$. aureus among food handlers. Accordingly, the current study investigated the prevalence and risk factors associated with skin carriage of enterotoxigenic $S$. aureus amongst food handlers working in three different food processing plants in Egypt.

\section{Materials and Methods}

\subsection{Data Collection}

Data collection occurred between April 2013 and October 2013. Personnel working in three different processing plants namely milk and dairy products, meat and poultry products as well as frozen/canned vegetable products were eligible to participate. Two hundred participants formally consented to involvement. Participants were verbally surveyed to gather information about age, gender, marital status, education and potential risk factor including duration in work, hand wash habit, presence of inflammatory skin condition and smoking.

\subsection{Microbiological Analysis}

Participant's hands and faces were well swabbed. Swabs were transferred to brain heart infusion broth, incubated at $37^{\circ} \mathrm{C}$ for $24 \mathrm{~h}$ and streaked onto the surface of Baird-Parker Agar Base plates (Oxoid CM0275, Basinggstoke, Hants, UK) supplemented with egg-yolk tellurite emulsion (Oxoid SR 0054) and aerobically incubated at $37^{\circ} \mathrm{C}$ for 24 - $48 \mathrm{~h}$. Three colonies per sample, showing typical colonial morphology of coagulase-positive Staphylococci, were subjected to Gram-staining, coagulase and catalase test. Gram, coagulase and catalase positive strains were confirmed with an agglutination Staphyloccci Plus test (Oxoid). Thereafter they were biochemically identified with API staph identification System for Staphylococcus aureus (bioMerieux MarcyI'Etoile, France). Definitive identification was based on the presence of DNA using DN-ase test, the presence of protein A and clumping factor using SLIDEX Staph plus (bioMerieux Marcy-I'Etoile, France). A strain of $S$. aureus NCTC 10788 (obtained from food science department, University of Wisconsin-Madison, US) was used as a reference strain.

Only one identified isolate, per positive individual, was investigated using an immunological technique to verify its ability to synthesize staphylococcal enterotoxin(s). The strains were grown in $10 \mathrm{ml}$ of tryptone soya broth (CM0219B, Oxoid) by shaking aerobically for $16-18 \mathrm{~h}$ at $37^{\circ} \mathrm{C}$. After centrifugation at $9000 \times \mathrm{g}$ for 20 min at $4^{\circ} \mathrm{C}$, the supernatant was tested for presence of staphylococcal enterotoxins and typed using Staphylococcal Enterotoxin Test Reversed Passive Latex Agglutination (SET-RPLA) (TD900 Oxoid Basinkstoke, Hampshire, UK) as recommended by the manufacturer's protocol. Negative controls were used with all the tested samples.

\subsection{Statistical Analysis}

Data collected were statistically analyzed using SAS version 8 (SAS Institute, Cary, NC, US). Proportions were 
compared using Pearson Chi-Square tests. The level of statistical significance was set at a $P$-value $\leq 0.05$.

\section{Results and Discussion}

Of the 200 participants, seventy five (38\%) were positive for S. aureus skin carriage of which $37 \%$ harboured enterotoxigenic strains as presented in Table 1. S. aureus colonization rates in the general population are estimated to be approximately $20 \%-32 \%$ [4]. The present study recorded a prevalence rate (38\%) that is slightly higher than the general population estimates. In spite of this, a 38\% carriage rate is within the ranges reported in several studies of food handlers in different food settings. A cross-sectional study conducted among 127 food handlers working in cafeterias in Ethiopia indicated that $16.5 \%$ of fingernail contents of the food handlers were cultured positive for S. aureus [7]. Another study done in Botswana reported that an even higher proportion (57.5\% out of 200 food handlers) tested positive for S. aureus [8]. Prevalence of enterotoxigenic S. aureus in food handlers is variable between industries and countries. Prevalence estimates from several small studies ranged from $2 \%$ of food handlers in Italy $(n=545)$ [9], 12\% of flight-catering staff in Finland $(n=136)$ [10], 19\% of restaurant workers in Chile $(n=102)$ [11] to $62 \%$ of fish processing factory workers in India $(n=87)$ [12]. In a study of nasal carriage of $S$. aureus amongst food handlers by the same investigators [13], a nasal carriage rate of $31 \%$ was reported that is higher than the skin carriage rate recorded in the current investigation. Although nasal carriage is expected to be higher than skin carriage, incompliance to strict Good Manufacturin Practice procedures in food settings may attribute to such finding. There exists a variation among $S$. aureus prevalence within regions, countries and even inside each country. Furthermore, studies target different populations encompassing students, hospital workers, infants, geriatrics, food handlers etc. and study carriage with respect to certain standard variables (viz., age, sex, health status, antibiotic intervention in a given time frame and others) within that group.

As seen from Table 1, subjects working in the milk and dairy processing plant recorded the highest prevalence rate (45\%) of colonization by $S$. aureus followed by the other two processing plants; meat and poultry products (36\%) and frozen/canned vegetables and juices (34\%) plants respectively. The difference in prevalence rates amongst the three study plants were significant $(P=-0.028)$, however, this prevalence cannot be exactly compared due to differences in habits and other environmental conditions that may exist in these plants.

Staphylococcal food poisoning is an intoxication that is caused by the ingestion of food containing pre-formed Staphylococcal Enterotoxin SE [14]. There are several different types of SE; enterotoxin A is most commonly associated with staphylococcal food poisoning. Enterotoxins D, E and H, and to a lesser extent B, G and I, have also been associated with staphylococcal food poisoning [15]. Food handlers carrying enterotoxin-producing $S$. aureus in their noses or on their hands are regarded as the main source of food contamination via direct contact or through respiratory secretions [14]. Results of the current investigation demonstrated that $14 \%$ of the examined subjects were enterotoxigenic S. aureus carriers. Enterotoxin A was the most recorded in 18 of the 28 isolates followed by enterotoxin C, B and D respectively. In surveys conducted on food handlers, S. aureus enterotoxins types A, B, C, D, and E have been isolated with varying frequency. In Kuwait, the majority of S. aureus isolates from hands of food workers was type $\mathrm{B}$, whereas those isolated from the nose were predominantly of types A and B (28\% and 28.5\% respectively) followed by types C and D (16.4\% and 3.5\% respectively) [16]. Enterotoxigenic S. aureus isolates from the nose, throat, hands and nails of food handlers in cafeterias of a Chilean restaurant were predominantly enterotoxin B and etnterotoxin D producers [17]. Meanwhile, another Chilean study and a Botswana's survey reported prevalence rate and predominance enterotoxin type that are in ac-

Table 1. Prevalence of skin carriage of S. aureus among food-handlers working in food processing plants.

\begin{tabular}{|c|c|c|c|c|}
\hline Food processing plant & $\begin{array}{c}\text { Total } \\
\text { subjects (n) }\end{array}$ & $\begin{array}{c}\text { S. aureus + ve } \\
\text { n (\%) }\end{array}$ & $\begin{array}{c}\text { Enterotoxigenic } \\
\text { SA + ve n (\%) }\end{array}$ & $\begin{array}{l}\text { Type of toxin(s) } \\
\text { produced }\end{array}$ \\
\hline Milk and dairy products & 42 & $19(45 \%)$ & $7(17 \%)$ & $\mathrm{A}^{* *}, \mathrm{C}^{*}, \mathrm{D}^{*}, \mathrm{AB}^{* *}$ and $\mathrm{ABC}^{*}$ \\
\hline Meat and poultry products & 91 & $33(36 \%)$ & $12(13 \%)$ & $\mathrm{A}^{* * *}, \mathrm{C}^{* *}, \mathrm{AB}^{*}, \mathrm{AC}^{*}, \mathrm{BC}^{*}, \mathrm{BD}^{*}, \mathrm{ABC}^{*}$ and $\mathrm{ACD}^{*}$ \\
\hline $\begin{array}{c}\text { Frozen/canned } \\
\text { vegetables and juices }\end{array}$ & 67 & $23(34 \%)$ & $9(13 \%)$ & $\mathrm{A}^{* * *}, \mathrm{C}^{*}, \mathrm{AC}^{* *}, \mathrm{BC}^{*}, \mathrm{BD}^{*}$ and $\mathrm{ACD}^{*}$ \\
\hline Total & 200 & 75 (38\%) & $28(14 \%)$ & \\
\hline
\end{tabular}

\footnotetext{
${ }^{*}=$ one strain; ${ }^{* *}=$ two strains; ${ }^{* * *}=$ three strains.
} 
cordance with results reported in the current survey [8] [11].

Recent studies substantiate that the mechanisms leading to $S$. aureus carriage are multi-factorial. Bacterial factors (e.g. staphylococcal toxins and cell wall-associated proteins), environmental factors (e.g. hospitalization and crowding), as well as, host susceptibility factors (e.g. immune suppression or other serious underlying diseases) play an important role. Colonization of S. aureus in human beings can be viewed as the net result of repellent and attracting forces that can be imposed by either of the interacting parties [18].

Survey response data in relation to prevalence of Staphylococcus aureus among the surveyed risk factors are given in Table 2. More than half of the respondents were males, aged between 20 - 40 and high school educated. Meanwhile about two thirds of the respondents had been employed for a period of less than 5 years and use water for hand wash at a frequency of $>1$ hr period. None of the surveyed factors demonstrated statistically significant association with staphylococcus skin carriage. These findings are in agreement with other studies that demonstrated that gender did not influence skin carriage of staphylococcus [19] [20] however, larger populationbased cross-sectional studies have reported higher risk of $S$. aureus nasal carriage among men as compared with women [21]. In literature, the association between gender as a fixed factor and staphylococcal carriage remains unclear. Earlier studies have also reported that age is a modifier for SA carriage, and the correlation between age and carriage was evident for high age groups as those over 70 [19] [22] and in some instances young age as teenagers (13 - 18 years) which was reported in a study investigating staphylococcal carriage on armpits of secondary school students [20]. The association between age and Staphylococcus aureus carriage in older age has been attributed to the fact that old participants have increased lifetime exposure to antibiotics which consequently affects prevalence rates. The current results are comparable to those estimated in previous records [20] [23] and the carriage rate cited was nearly the same among the two age groups investigated (20 - 40 and 40 - 60).

\begin{tabular}{|c|c|c|c|}
\hline Factor & Total (n) & S. aureus + ve n (\%) & $p$ value \\
\hline \multicolumn{4}{|l|}{ Gender } \\
\hline Male & 115 & $42(37 \%)$ & \multirow{2}{*}{0.612} \\
\hline Female & 85 & 33 (39\%) & \\
\hline \multicolumn{4}{|l|}{$\underline{\text { Age }}$} \\
\hline 20 - 40 years & 103 & 36 (35\%) & \multirow{2}{*}{0.521} \\
\hline$>40-60$ years & 97 & 39 (40\%) & \\
\hline \multicolumn{4}{|l|}{ Education } \\
\hline High school & 104 & 39 (38\%) & \multirow{2}{*}{0.610} \\
\hline elementary & 96 & 36 (37\%) & \\
\hline \multicolumn{4}{|l|}{ Marital status } \\
\hline Single & 140 & 49 (35\%) & \multirow{2}{*}{0.381} \\
\hline Married & 60 & $26(43 \%)$ & \\
\hline \multicolumn{4}{|l|}{ Duration in work } \\
\hline$<5$ years & 136 & 45 (33\%) & \multirow{2}{*}{0.623} \\
\hline$\geq 5$ years & 64 & $30(47 \%)$ & \\
\hline \multicolumn{4}{|c|}{ Frequency of hand wash } \\
\hline$<$ an hour & 63 & $25(40 \%)$ & \multirow{2}{*}{0.613} \\
\hline$>1$ hour & 137 & $50(36 \%)$ & \\
\hline \multicolumn{4}{|c|}{ Method of hand wash } \\
\hline Water & 116 & $44(38 \%)$ & \multirow{2}{*}{0.412} \\
\hline Soap and water & 84 & 31 (37\%) & \\
\hline \multicolumn{4}{|c|}{ Incidence of inflammatory skin condition } \\
\hline Yes & 19 & $7(37 \%)$ & \\
\hline No & 181 & 68 (38\%) & 0.520 \\
\hline \multicolumn{4}{|l|}{ Smoking } \\
\hline Smoker & 108 & 39 (36\%) & \multirow{2}{*}{0.393} \\
\hline Non smoker & 92 & 36 (39\%) & \\
\hline
\end{tabular}

$p$-value $<0.05$ was considered significant. 
There is evidence from large population-based studies for an inverse association between current smoking and S. aureus carriage among both men and women; in the Rotterdam study, smoking was associated with a $36 \%$ reduced risk and in the Tromso Staph and Skin Study the S. aureus carriage rate was 28\% lower in smokers than in non-smokers $(\mathrm{P}<0.01)$ [24] [25]. The results in the current investigation were in accordance with previous findings as carriage rates in non smokers (39\%) were higher than that recorded in smokers. Possible explanations for the suggested protective effect of smoking include the bactericidal activity of cigarette smoke and the increased immune activity associated with smoking-induced hypoxia [26].

Several modifiable factors related to staphylococcal skin carriage have been investigated, research reported discrepancies among the correlation of these factors with skin harbouring of staphylococcus. It was reported that variables such as the type of soap used, bathing and shaving frequency and use of deodorant had no effect on $S$. aureus skin carriage in the armpits of investigated individuals [20]. In another study on staphylococcal carriage in correctional facilities as jails and prisons, factors associated with MRSA skin harbour were multiple of which antibiotic use in the previous year and lower rate of showering were significant factors influencing skin carriage [27]. The view that hand washing insignificantly affected staphylococcal skin carriage was opposed in a Chilean study which demonstrated that washing hands and skin surfaces has minimal effect on reducing $S$. aureus cell numbers on humans, largely because S. aureus is part of the resident flora of skin [17]. Skin diseases that alter the epithelium are reported to be an influential factor on S. aureus carriage. Atopic dermatitis (AD) is a pruritic skin disease characterized by barrier dysfunction of the skin and chronic inflammation [28]. Several smaller clinical studies have shown strong associations between $\mathrm{AD}$ and $S$. aureus colonisation of the skin and nose. However, others observed no association between S. aureus load and disease severity [24]. In the current investigation there was no significant association between the presence of chronic inflammatory skin condition and $S$. aureus carriage. Moreover, the carriage rates among individuals with/without inflammatory skin condition were nearly the same.

From population based studies, there are numerous reports of factors associated with $S$. aureus carriage. Observational studies of $S$. aureus carriage discussed the influence of bacterial, host and environmental/modifiable factors which might have influence on the relationship. However, to extract specific host determinants can be challenging, since variation in carriage rates are likely to be multifactorial and single determinants would be very hard to identify. Still, epidemiological studies can unravel valuable information for formulating hypothesis about complexity that might be involved in carriage.

\section{Acknowledgements}

Financial support for this research was provided by the Agencia Espa nola de Cooperaci’on Internacional para el Desarrollo (A/019106/08, A/025113/09 and A1/035779/11).

\section{References}

[1] ECD/WHO (2003) Foodborne Disease in OECD Countries: Present State and Economic Costs. http://dx.doi.org/10.1787/9789264105386-en

[2] FDA (2009) FDA Report on the Occurrence of Foodborne Illness Risk Factors in Selected Institutional Food Service, Restaurant and Retail Food Store Facility Type. http://www.cfsan.fda.gov/ acrobat/retrsk2.pdf

[3] Verkaik, N.J., Benard, M., Boelens, H.A., De Vogel, C.P., Nouwen, J.L., Verbrugh, H.A., Melles, D.C., van Belkum, A. and van Wamel, W.J. (2011) Immune Evasion Cluster Positive Bacteriophages Are Highly Prevalent among Human Staphylococcus aureus Strains, but They Are Not Essential in the First Stages of Nasal Colonization. Clinical Microbiology and Infection, 17, 343-348. http://dx.doi.org/10.1111/j.1469-0691.2010.03227.x

[4] Wertheim, H.F.L., Melles, D.C., Vos, M.C., van Leeuwen, W., van Belkum, A., Verbrugh, H.A. and Nouwen, J.L. (2005) The Role of Nasal Carriage in Staphylococcus aureus Infections. Lancet Infectious Diseases, 5, 751-762. http://dx.doi.org/10.1016/S1473-3099(05)70295-4

[5] Jordá, G.B., Marucci, R.S., Guida, A.M., Pires, P.S. and Manfredi, E.A. (2012) Carriage and Characterization of Staphylococcus aureus in Food Handlers. Revista Argentina de Microbiologia, 44, 101-104.

[6] National Disease Surveillance Centre (NDSC) (2004) Preventing Foodborne Disease: A Focus on the Infected Food Handler. http://www.thehealthwell.info/node/75597

[7] Andargie, G., Kassu, A., Moges, F., Tiruneh, M. and Huruy, K. (2008) Prevalence of Bacteria and Intestinal Parasites among Food-Handlers in Gondar Town, Northwest Ethiopia. Journal of Health, Population and Nutrition, 26, 451- 
455.

[8] Loeto, D., Matsheka, M.I. and Gashe, B.A. (2007) Enterotoxigenic and Antibiotic Resistance Determination of Staphylococcus aureus Strains Isolated from Food Handlers in Gaborone, Botswana. Journal of Food Protection, 70, 2764-2768.

[9] Talarico, F., Roccia, E. and Nero, D. (1997) Prevalence of Enterotoxigenic Staphylococcus in Food Handlers in the Province of Catanzaro (Italy). Igiene Moderna, 107, 137-142.

[10] Hatakka, M., Björkroth, K.J., Asplund, K., Mäki-Petäys, N. and Korkeala, H.J. (2000) Genotypes and Enterotoxicity of Staphylococcus aureus Isolated from the Hands and Nasal Cavities of Flight-Catering Employees. Journal of Food Protection, 63, 1487-1491.

[11] Figueroa, G., Navarrete, P., Caro, M., Troncoso, M. and Faundez, G. (2002) Carriage of Enterotoxigenic Staphylococcus aureus in Food Handlers. Revista Medica de Chile, 130, 859-864.

[12] Simon, S.S. and Sanjeev, S. (2007) Prevalence of Enterotoxigenic Staphylococcus aureus in Fishery Products and Fish Processing Factory Workers. Food Control, 18, 1565-1568. http://dx.doi.org/10.1016/j.foodcont.2006.12.007

[13] El-Shenawy, M., El Hosseiny, L., Tawfeek, M., El-Shenawy, M., Baghdadi, H., Saleh, O., Manes, J. and Soriano, J.M. (2013) Nasal Carriage of Enterotoxigenic Staphylococcus aureus and Risk Factors among Food Handlers-Egypt. Food and Public Health, 3, 284-288.

[14] Argudin, M.A., Mendoza, M.C. and Rodicio, M.R. (2010) Food Poisoning and Staphylococcus aureus Enterotoxins. Toxins, 2, 1751-1773. http://dx.doi.org/10.3390/toxins2071751

[15] Pinchuk, I.V., Beswick, E.J. and Reyes, V.E. (2010) Staphylococcal Enterotoxins. Toxins, 2, 2177-2197. http://dx.doi.org/10.3390/toxins2082177

[16] Udo, E.E., Al-Bustan, M.A., Jacob, L.E. and Chugh, T.D. (1999) Enterotoxin Production by Coagulase-Negative Staphylococci in Restaurant Workers from Kuwait City May Be a Potential Cause of Food Poisoning. Journal of Medical Microbiology, 48, 819-823. http://dx.doi.org/10.1099/00222615-48-9-819

[17] Soriano, J.M., Font, G., Molto, J.C. and Males, J. (2002) Enterotoxigenic Staphylococci and Their Toxins in Restaurant Foods. Trends in Food Science and Technology, 13, 60-67. http://dx.doi.org/10.1016/S0924-2244(02)00030-4

[18] van Belkum, A., Melles, D.C., Nouwen, J., van Leeuwen, W.B., van Wamel, W., Vos, M.C., Wertheim, H.F. and Verbrugh, H.A. (2009) Co-Evolutionary Aspects of Human Colonisation and Infection by Staphylococcus aureus. Infections, Genetics and Evolution, 9, 32-47. http://dx.doi.org/10.1016/j.meegid.2008.09.012

[19] Warren, R. (2012) Staphylococcus aureus A Cross Sectional Study of Prevalence and Risk Factors in One General Practice. Australian Family Physician, 41, 325-328.

[20] Ibe, S.N. and Wariso, B.A. (2005) Carriage of Staphylococcus aureus on Armpits of School and University Students in Port Harcourt, Nigeria. African Journal of applied Zoology and Environmental Biology, 7, 125-130.

[21] Zanger, P., Nurjadi, D., Gaile, M., Gabrysch, S. and Kremsner, P.G. (2012) Hormonal Contraceptive Use and Persistent Staphylococcus aureus Nasal Carriage. Clinical Infectious Diseases, 55, 1625-1632. http://dx.doi.org/10.1093/cid/cis778

[22] Donker, G.A., Deurenberg, R.H., Driessen, C., Sebastian, S., Nijs, S. and Stobberingh, E.E. (2009) The Population Structure of Staphylococcus aureus among General Practice Patients from The Netherlands. Clinical Microbiology and Infection, 15, 137-143. http://dx.doi.org/10.1111/j.1469-0691.2008.02662.x

[23] Breuer, K., Haussler, S., Kapp, A. and Werfel, T. (2002) Staphylococcus aureus: Colonizing Features and Influence of an Antibacterial Treatment in Adults with Atopic Dermatitis. British Journal of Dermatology, 147, 55-61. http://dx.doi.org/10.1046/j.1365-2133.2002.04872.x

[24] Sollid, J.U., Furberg, A.S., Hanssen, A.M. and Johannessen, M. (2013) Staphylococcus aureus: Determinants of Human Carriage. Infections, Genetics and Evolution. http://dx.doi.org/10.1016/j.meegid.2013.03.020

[25] Olsen, K., Falch, B.M., Danielsen, K., Johannessen, M., Sollid, J.U., Thune, I., Grimnes, G., Jorde, R., Simonsen, G.S. and Furberg, A.S. (2012) Staphylococcus aureus Nasal Carriage Is Associated with Serum 25-Hydroxyvitamin D Levels, Gender and Smoking Status. The Tromso Staph and Skin Study. European Journal of Clinical Microbiology and Infectious Diseases, 31, 465-473. http://dx.doi.org/10.1007/s10096-011-1331-x

[26] Wang, J.T., Liao, C.H., Fang, C.T., Chie, W.C., Lai, M.S., Lauderdale, T.L., Lee, W.S., Huang, J.H. and Chang, S.C. (2009) Prevalence of and Risk Factors for Colonization by Methicillin-Resistant Staphylococcus aureus among Adults in Community Settings in Taiwan. Journal of Clinical Microbiology, 47, 2957-2963. http://dx.doi.org/10.1128/JCM.00853-09

[27] Maree, C.L., Eells, S.J., Tan, J., Bancroft, E.A., Malek, M., Harawa, N.T., Lewis, M.J., Santana, E. and Miller, L.G. (2010) Risk Factors and Colonization with Community Associated Methicillin Resistant Staphylococcus aureus in the Los Angeles County Jail: A Case Control Study. Clinical Infectious Diseases, 51, 1248-1257. 
M. El-Shenawy et al.

http://dx.doi.org/10.1086/657067

[28] Bieber, T. (2008) Atopic Dermatitis. The New England Journal of Medicine, 358, 1483-1494. http://dx.doi.org/10.1056/NEJMra074081 